\title{
EFFECTS OF MORPHINE ON SINGLE UNIT ACTIVITY OF THE AMYGDALA IN CATS
}

\author{
Toshiji MIYAGAWA, Shinobu SAKURADA*, Kensuke KISARA, \\ Takumi SATO, Ryuichiro ANDOH, Norio TAKAHASHI, \\ Tsukasa SAKURADA and Keisetu SHIMA \\ Department of Pharmacology. Tohoku College of Pharmacy, \\ Komatsushima, Sendai 983, Japan
}

Accepted June 3, 1982

\begin{abstract}
Single neuronal activity has been recorded extra-cellularly from the nucleus amygdaloideus centralis (pars lateralis) (Acl), the nucleus amygdaloideus centralis (pars medialis) $(\mathrm{Acm})$, the nucleus amygdaloideus basalis (pars magnocellularis) (Abm), the nucleus amygdaloideus lateralis (Al), and the nucleus amygdaloideus basalis (pars parvocellularis) (Abp). The majority of the Acl. Acm, and Abm neurons were excited by nociceptive stimulation such as pinching the skin with serrated forceps and/or intraarterial injection of bradykinin. The nociceptive neurons were also driven by non-nociceptive stimulation such as tapping of deep tissues and bending hairs with an air-puff. Their receptive fields were large. After the intravenous administration of morphine, all nociceptive neurons became unresponsive to nociceptive stimuli, although they were driven by nonnociceptive stimuli. Intravenous naloxone antagonized the antinociceptive action of morphine. This suggests that morphine has selective and inhibitory effects on impulse transmission to these nociceptive neurons, and the amygdala, especially the Acl. Acm, and Abm, plays an important role in central nociceptive processing.
\end{abstract}

It has been shown that some of the amygdala neurons respond to sciatic nerve stimulation (1), but nociceptive stimuli were not used in this report.

On the other hand, it has been shown that the amygdala of monkey brain contained the greatest amounts of opiate binding receptor and a morphine-like peptide, methionineenkephalin (2, 3). Moreover, Rodgers (4) reported that bilateral microinjection of morphine into the cortico-medial amygdala produced a dose-dependent increase in the aversive threshold. However, no experiments have yet been made which allows one to

"To whom all correspondence should be addressed. evaluate the effects of morphine on unit activities of the amygdala.

An attempt is made in this paper to determine whether the amygdala neurons are driven by the peripheral nociceptive stimuli, and a further object of this work is to study the antinociceptive action of morphine on the neurons of the amygdala.

\section{MATERIALS AND METHODS}

Experiments were performed on 38 adult cats. The animals were initially anesthetized with sodium pentobarbital (Nembutal) at $35 \mathrm{mg} / \mathrm{kg}$ i.p. Tracheal and vascular cannulation were performed, all operative wounds were carefully closed with sutures, 
and the animals were placed in a stereotaxic apparatus. The skull was trephined over the amygdala, the metal chamber mounted with dental acrylic, the dura removed, and bleeding into the chamber was carefully halted. The wound borders and pressure points were infiltrated with xylocaine jelly prior to and periodically after the beginning of recording. During recording, the animals were given gallamine triethiodide (Flaxidil) and artificially ventilated. Rectal temperature was maintained approximately at $38^{\circ} \mathrm{C}$ by means of a homeothermic blanket system. To reduce movement by respiration and heart beat, a modification of the "closed-heat" technique was used (5).

The impulse activity from a single neuron. whose electrical sign was initially a negative spike potential to the ground, was recorded with a stainless steel microelectrode. The electrodes had tip diameters of $1-3 / \mathrm{mm}$ that were coated with an insulating paint, and they had resistances of $1-3$ megohms at a test frequency of $1000 \mathrm{~Hz}$.

Neuronal activity was displayed on a cathode-ray oscilloscope, and a window discriminator was employed to identify single neuron impulses. The impulses were also monitored through a loudspeaker. Two electrodes were advanced dorsoventrally into the bilateral amygdala according to the stereotaxic co-ordinates of Jasper and Ajmone-Marsan (6). The electrodes were advanced until several units were recorded simultaneously within each of the target nuclei. This required repositionings until satisfactory single unit discharges were made from the cortical somatic sensory areas. These variables as well as neuronal impulse sequences were stored on FM magnetic tape with the recorded of the stimulus and the drug application. The following modes of non-nociceptive peripheral stimulation were used: bending hairs with an air-puff, touch on the skin, tap of deep tissues (5). Nociceptive stimuli were applied by pinching the skin with serrated forceps that were adjusted to be clearly noxious when applied to the investigator (7). A small amount of bradykinin (3 $\mu \mathrm{g}$ in $0.005 \mathrm{ml}$ saline) was injected into the deep femoral artery through a polyethylene of cannula which was inserted retogradely into a collateral of the right artery stimulation of the whole posterior (8). The fact that animals were not suffering pain was shown by the occurrence of spindle bursts and slow waves on the continuously recording EEG.

Each animal received morphine (1 $\mathrm{mg} / \mathrm{kg}$ ) intravenously only once. In some animals, naloxone $(0.2 \mathrm{mg} / \mathrm{kg})$ was given intravenously from $15 \mathrm{~min}$ after the administration of morphine. At the end of each experiment, an anodal current of 20 / $\mathrm{A}$ was passed through the electrode for $15 \mathrm{sec}$ to mark the position of the recording electrode tip. The animal was sacrificed under deep pentobarbital anesthesia and perfused with $10 \%$ formalin mixed with $2 \%$ potassium ferrocyanide to obtain a Prussian blue spot. After the fixation, frontal serial frozen section of $25 \mu \mathrm{m}$ thickness were stained with $0.2 \%$ cresyl violet (5).

The neuronal impulse sequences recorded on the magnetic tape were reproduced through the window discriminator and processed for the purpose of data reduction by the 7SO6 computer.

\section{RESULTS}

Neurons types, location and receptive field: Forty-eight neurons in the amygdala were examined. Concerning spontaneous single unit activity, 45 neurons were irregular, 2 neurons burst, and 1 neuron regular (Fig. 1). Thus distinct types of driven neurons were identified based on the forms of peripheral stimuli that adequately existed in their receptive areas (Table 1 ).

Plotted in Fig. 2 are anatomical loci of the 48 neurons which were responsive to or unresponsive to nociceptive and non- 


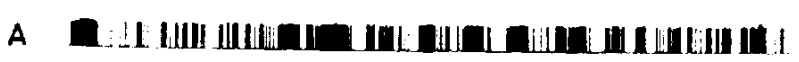
$5 \sec$

B
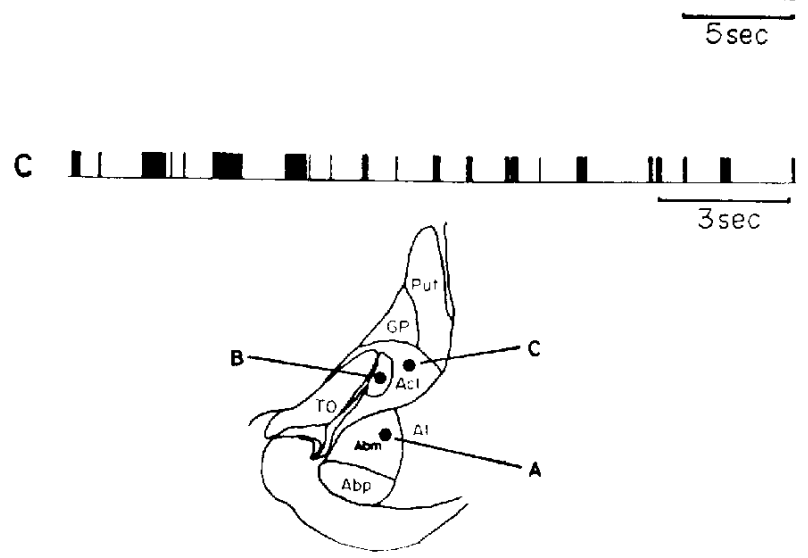

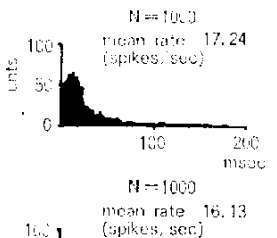

moth rate 16.13
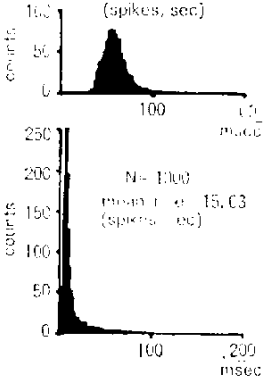

Fig. 1. Three typical spontaneous unit discharges of the amygdala.

Table 1. Modalities of effective stimuli and anatomical location of neurons

\begin{tabular}{lccccc}
\hline Neuron Type & Acl & Acm & Abm & Abp & Al \\
\hline Pinch+Brady+Non-nociceptive & 4 & 2 & 12 & 0 & 0 \\
Pinch +Non-nociceptive & 1 & 2 & 1 & 0 & 0 \\
Non-nociceptive & 4 & 1 & 1 & 0 & 1 \\
Not driven & 2 & 1 & 5 & 3 & 8 \\
Total & 11 & 6 & 19 & 3 & 9 \\
\hline
\end{tabular}

Pinch: Pinching skin with toothed forceps

Brady: Bradykinin

Non-nociceptive: Bending hairs with a blower and/or tapping and deep tissues.

nociceptive stimuli. Seven out of 48 neurons were excited only by non-nociceptive stimulation. 4 by both non-nociceptive and pinch stimulation, and 18 by pinch and bradykinin stimuli as well as non-nociceptive stimuli. The remaining 19 did not respond to any somatic sensory stimulation. Thus 22 neurons responded to nociceptive stimulation were found in the Acl. Acm, and Abm, but not in the $\mathrm{Al}$ and $\mathrm{Abp}$. The somatic receptive fields of the majority of the nociceptive and non-nociceptive neurons were wide and either contralateral or bilateral. A somatotopic organization of neurons was not found in the nuclei studied.

Effects of morphine on spontaneous unit discharges of the amygdala neurons: The effects of morphine on spontaneous unit discharges in 25 amygdala neurons are summarized in Table 2. When morphine was administered, spontaneous firing rates were increased in 15, decreased in 5, and unaltered in 5 out of 25 amygdala neurons examined (Table 2). The morphine-induced augumen- 


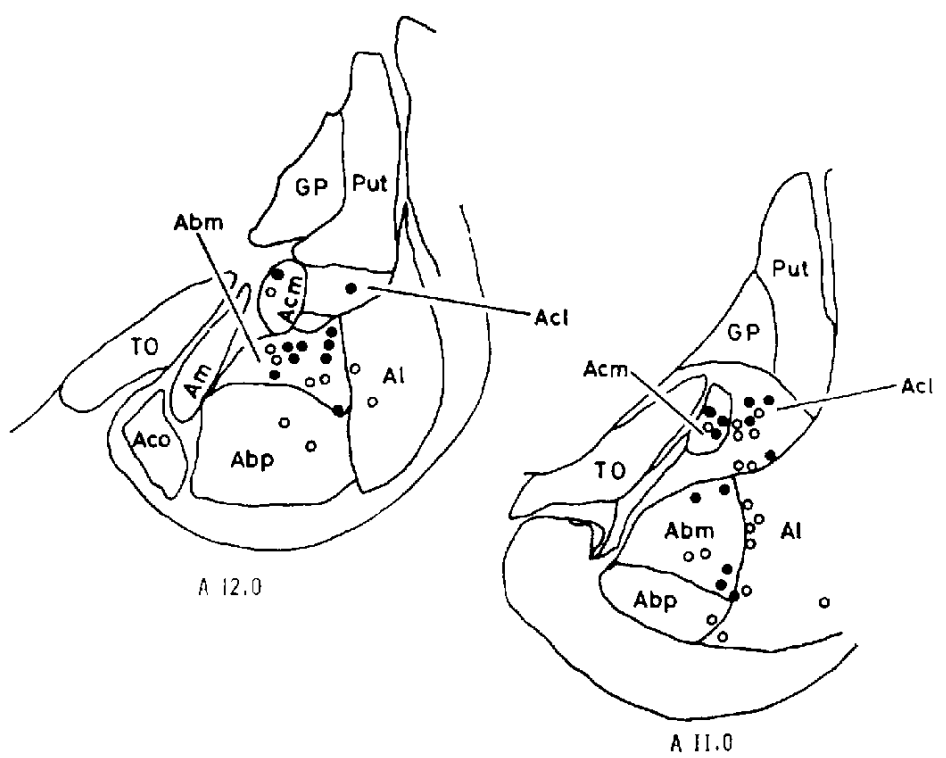

Fig. 2. Location of somesthotic nourons studied in the amygdala. Loci of 48 neurons are plotted on frontal planes that extend from AP 11.0 to 12.0. The recording sites of the right amygdala are coverniently plotted to the corresponding positions of the left side along with the actual locations. Abbreviations according to the stereotaxic atlas of Jasper and Ajmone-Marsan unless otherwise stated.

Table 2. Effects of morphine on spontanoous discharges of amygdala neurons

\begin{tabular}{lcccc}
\hline Properties & $\begin{array}{c}\text { Number of } \\
\text { neurons }\end{array}$ & Suppressed & Accele, ated & Non-responsive \\
\hline Nociceptive+Non-nociceptive & 18 & 4 & 10 & 4 \\
Non-nociceptive & 4 & 1 & 3 & 0 \\
Not driven & 3 & 0 & 2 & 1 \\
Total & 25 & 5 & 15 & 5 \\
\hline
\end{tabular}

Nociceptive: Pinching skin with toothed forceps.

Non-nociceptive: Bending hairs with a blower and/or tapping and deep tissues.

tation and suppression of amygdala neuronal activity were antagonized by naloxone. Figure 3 shows that morphine increased the spontaneous firing rate of the amygdala neurons to 21.7 spikes $/ \mathrm{sec}$ from $5.7 \mathrm{spikes} / \mathrm{sec}$, and subsequent injection of naloxone antagonized the narcotic effect.

The morphine effects on the spontaneous firing rate were unrelated to the responsiveness of the unit to nociceptive stimuli.

Antinociceptive action of morphine: The antinociceptive action of morphine upon nociceptive neurons was examined. All of the
22 nociceptive neurons examined became unresponsive to nociceptive stimuli such as skin pinch after administration of morphine (Fig. 4). In contrast, there was no appreciable change of responsiveness to non-nociceptive stimuli such as deep tissues tap and hair bending compared with control responses. All of 4 non-nociceptive neurons examined were unaffected by administration of morphine. In the 18 nociceptive neurons, naloxone given $15 \mathrm{~min}$ after morphine completely reversed the antinociceptive action by morphine (Fig. 4). 
before drug

. 1 :

morphine $1 \mathrm{mg} / \mathrm{kg}$ i.v.

15 min after

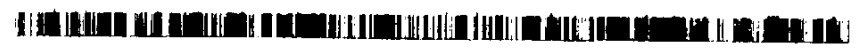
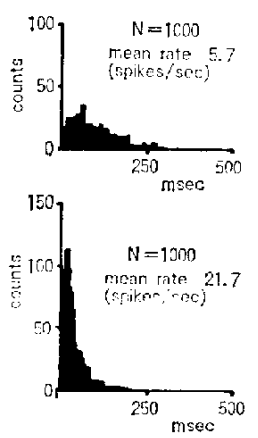

noloxone $0.2 \mathrm{mg} / \mathrm{kg}$ i.v.

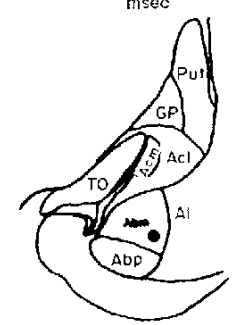

Fig. 3. Effects of morphine and naloxone on spontaneous unit discharges in the amygdala. Each histogram consists of ono thousand spikes.

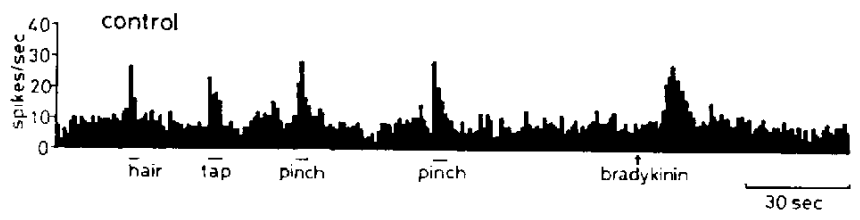

morphine img/kg i.v.

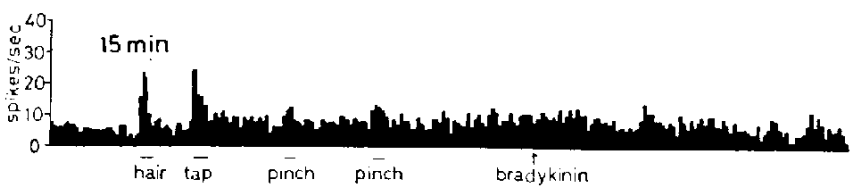

naloxone $0.2 \mathrm{mg} / \mathrm{kg}$ i.v.

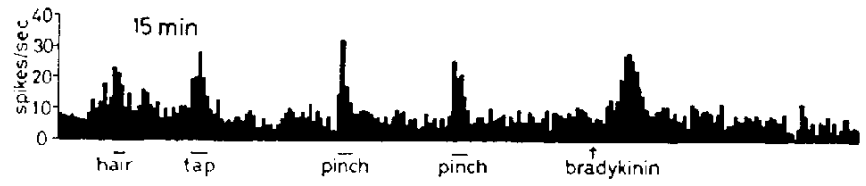

Fig. 4. Effects of morphine and naloxone on the single unit activity of the amygdala to nociceptive stimulus and non-nociceptive stimulus. Ordinate: number of discharges per sec. Abscissa: time in sec.

\section{DISCUSSION}

Neurons responsive to nociceptive stimuli such as bradykinin or pinch were found in the
Acl. Abm, and Acm. Amygdala neurons in cats responding to sciatic nerve and olfactory bulb stimulations have been observed by Creutzfeldt et al. (9). Bradykinin effects are 
mediated by a small fiber which innervates deep tissues and visceral organs (10). Large amounts of intra-arterial bradykinin (30-70 $\mu \mathrm{g})$ appear much less specific and activate cell firing by both nociceptive and nonnociceptive stimuli (11). Since we used a small amount of bradykinin, the nature of bradykinin-induced pain resembles deep. visceral, or protophathic pain more than superficial and cutaneous pain (10).

Responses to nociceptive stimuli were observed in 22 out of 48 neurons. These nociceptive neurons were localized in the $\mathrm{Acm}, \mathrm{ACl}$, and $\mathrm{Abm}$, while there were no nociceptive neurons in the Abp and Al. Thus the present results suggest that the neurons in the $\mathrm{Acl}, \mathrm{Acm}$, and $\mathrm{Abm}$ may be related to emotional changes produced by nociceptive stimuli.

The regional distribution of substance $P$ concentration in the central nervous system is remarkedly similar to that for opiate receptor binding sites $(12,13)$. Since substance $P$ may play an excitatory role in the spinal pain pathway (14), this substance acts as a transmitter or modulator of excitability at the first afferent synapse; and it is particularly abundant in the medial amygdala $(15,16)$. Therefore, a correlation between this region and nociceptive or analgesia can be presumed. It was reported that the medial amygdala receives a $\beta$-endorphinergic input from the basal hypothalamus (17), while the central nucleus contains a dense network of enkephalinergic interneurons (18). In addition, Rodgers (4) reported that the micro-injection of morphine into the medial amygdala produced a dose dependent increase in aversive thresholds. Though morphine efficacy in the tail flick test was not modified by the amygdala complex lesion, the analgesic effects of morphine on the vocalization threshold were markedly reduced (19). This result that these differential effects on the two nociceptive threshold and morphine analgesia were produced by the bilateral amygdala complex lesion, suggests that amygdala opiate systems may play a role in modulation of integrated responses to nociceptive stimulation (19). We found herein that morphine suppressed the response to nociceptive stimuli and did not affect responses to nonnociceptive stimuli in the amygdala neural activity. It seems likely, therefore, that the amygdala may be involved in a part of the possible mechanism for the antinaciceptive action of the narcotic agonist.

Morphine has both depressant and excitatory actions on neurons of various regions in the brain $(20,21)$. Morphine elicits similar behavioral responses in the cat as those observed with stimulation of the amygdala (22. 23). Therefore, excitation in the amygdala neurons induced by morphine may be involved in producing such behavioral changes.

\section{REFERENCES}

1) Machne, $X$. and Segundo, J.P.: Unitary responses to afferent volleys in amygdaloid complex. J. Neurophysiol. 19, 232-240 (1956)

2) Kuhar, M.J., Pert, C.B. and Snyder, S.H.: Regional distribution of opiate receptor binding in monkey and human brain. Nature 245, 447450 (1973)

3) Simantov, R., Kuhar, M.J., Posternak, G.W. and Snyder, S.H.: The regional distribution of morphine-like factor enkephalin in monkey brain. Brain Res. 106, 189-197 (1976)

4) Rodgers, R.J.: Elevation of aversive threshold in rats by intra-amygdaloid injection of morphine sulfate. Pharmacol. Biochem. Behav, 6, 385390 (1977)

5) Nishioka, S. and Nakahama, H.: Peripheral somatic activation of neurons in the cat red nuc!eus. J. Neurophysiol. 36, 296-306 (1973)

6) Jasper, H.H. and Ajmone-Marsan, C.: A stereotaxic atlas of the diencephalon of cat. Natl. Res. Council Canada. Ottawa (1959)

7) Le bars, D., Dickenson, A.H. and Besson, J.M.: Diffuse noxious inhibitory controls (DNIC). I. Effects on dorsal horn convergent neurons in rat. Pain 6, 283-304 (1979)

8) Lombard, M.C., Guilbaud, G. and Besson, J.M.: Effects of the intra-arterial injection of brady- 
kinin into limbs, upon the activity of mesencephalic reticular units. Europ. J. Pharmacol. 30, 298-308 (1975)

9) Creutzfeldt, O.D., Bell, F.R. and Adey, W.R.: The activity of neurons in the amygdala of the cat following afferent stimulation. Progr. Brain Res. 3, 31-49 (1963)

10) Krauthamer, G., McGuinness, C. and Gottesman, L.: Unit responses in the ventrobasal thalamus (VPL) of the cat to bradykinin injected into somatic and visceral arteries. Brain Res. Bull. 2, 299-306 (1977)

11) Belcher, G.: The effects of intra-arterial bradykinin, histamine, acetylcholine and prostaglandin $E_{1}$ on nociceptive and non-nociceptive dorsal horn neurons of the cat. Europ. J. Pharmacol. 56, 385-395 (1979)

12) Snyder, S.H.: Opiate receptor in normal and drug altered brain function. Nature 257, 185187 (1975)

13) Kanazawa, I. and Jessel, T.: Post-mortem changes and regional distribution of substance $P$ in the rat and mouse nervous system. Brain Res. 117, 362-367 (1976)

14) Henry, J.L.: Effects of substance $P$ on functionally identified units in cats spinal cord, Brain Res. 114, 439-451 (1976)

15) Rodgers, R.J.: Attenuation of morphine analgesia in rats by intra-amygdaloid injection of morphine. Brain Res. 130, 156-162 (1977)

16) Emson, P.C., Jessel, T., Paxinos, G. and Cuello, A.C.: Substance $P$ in the amygdaloid camplex, bed nucleus and stria terminalis of the brain. Brain Res. 149, 97-105 (1978)

17) Barchas, J.D., Akil, D.H., Eliott, G., Holman, R.B. and Watson, S.J.: Behavioural neurochemistry: neuroregulator and behavioural states. Science 200, 964-973 (1978)

18) Sar, M., Stumpf, W.E., Miller, R.J., Chang, K.J. and Cuatrecasas, P.: Immunohistochemical localization of enkephalin in rat brain and spinal cord. J. comp. Neurol. 182, 17-38 (1978)

19) Calvino, B., Levesque, G. and Besson, J.M.: Effects of bilateral amygdalectomy in morphine analgesia in the rat. Third World Congress on Pain of international Association for the Study of Pain. Abstract S195 (1981)

20) Kerr, F.W.L., Triplett, J.N, Jr. and Beeler, G.W.: Reciprocal (push-puli) effects of morphine on single units in the ventromedial lateral hypothalamus and influences on other nuclei: with a comment on methadone effects during withdrawal from morphine. Brain Res. 74, 81-108 (1974)

21) Lee, H.K. and Wang, S.C.: Mechanism of morphine induced miosis in the dog. J. Pharmacol. exp. Ther. 192, 415-431 (1975)

22) Mckenzie, J.S. and Beechey, N.R.: The effects of morphine and pethidine on somatic evoked responses in the midbrain of the cat, and their revelance to analgesia. Electroen. Neurophysiol. 14, 501-519 (1962)

23) Kaada, B.R., Anderson, P. and Jansen, J., Jr.: Stimulation of the amygdaloid nuclear complex in unanesthetized cats. Neurology, Minneap. 4, 48-64 (1954) 